\title{
Primary infections of Epstein-Barr virus, cytomegalovirus, and human herpesvirus-6
}

\author{
Li-Min Huang, Chin-Yun Lee, Mei-Hwei Chang, Jung-Der Wang, Ching-Ying Hsu
}

\begin{abstract}
A total of 121 infants entered a cohort serological study of primary infections with herpesviruses. All of them had seven samples of blood available: the first sample was taken soon after birth, the other six were taken at 1 , $2,3,6,12$, and 14 months of age. One sample of maternal blood was collected immediately after delivery. All blood samples were tested for antibodies against cytomegalovirus, Epstein-Barr virus, and human herpesvirus-6 (HHV-6).

Primary cytomegalovirus infection occurred early; the cumulative infection rates were $1 \cdot 7 \%, 8 \cdot 3 \%, 18 \cdot 3 \%, 25 \%, 52 \cdot 5 \%$, and $65 \%$ by the ages of $1,2,3,6,12$, and 14 months, respectively. Epstein-Barr virus infection was not seen before 3 months of age and slowly emerged thereafter, reaching a cumulative rate of $1.7 \%, 11.6 \%, 21.5 \%$ at the ages of 6,12 , and 14 months, respectively. Primary HHV-6 infection was also a rare event in the first three months of life, but peaked between 6 and 12 months of age. No detectable risk factors were associated with primary Epstein-Barr virus or HHV-6 infection. The risk factors associated with cytomegalovirus infection included breast feeding, fewer children in household, and care by a babysitter.
\end{abstract}

(Arch Dis Child 1993; 68: 408-411)

There are at least six members of the human herpesviridae: herpes simplex virus type I and II, varicella zoster virus, cytomegalovirus, Epstein-Barr virus, and human herpesvirus- 6 (HHV-6). All human herpesviruses are similar in structure and general genome layout. They are all capable of inducing human diseases and maintaining a latent state in the host after primary infection. ${ }^{1}$ The primary infections of different herpesviruses usually occur in the first few years of life, but with substantial differences among them. In this study we focus on the latter three viruses: cytomegalovirus, Epstein-Barr virus, and HHV-6. Cytomegalovirus is an important aetiological agent of congenital and perinatal virus infections, ${ }^{23}$ to which EpsteinBarr virus has been rarely linked. ${ }^{+}$It has been speculated that, in addition to environmental factors, virus reactivation during pregnancy and maternal antibody have important roles in the timing of primary infection.' HHV-6 is a new member of human herpesviruses and was first characterised in $1986 . .^{5}$ Earlier we have shown that primary HHV-6 infections usually occur between six and 12 months of life. ${ }^{6}$ Here we present the cohort study of cytomegalovirus, Epstein-Barr virus, and HHV-6. By comparing the different patterns of primary infections we hope to understand better the biology and mode of spread of these three viruses.

\section{Subjects and methods}

SUBJECTS

From January 1988, 121 newborns were recruited to enter a study for the efficacy of recombinant hepatitis $B$ vaccine. Their mothers were all hepatitis B surface antigen ( $\mathrm{HBsAg}$ ) positive; 109 of them were hepatitis e antigen (HBeAg) positive. All infants had received four doses of recombinant hepatitis $B$ vaccines (Engerix-B, SmithKline and Biologicals, Belgium) at $0,1,2$, and 12 months of age. On the first day of life, $0.5 \mathrm{ml}$ of hepatitis B immunoglobulin was given to infants born to $\mathrm{HBeAg}$ positive mothers.

\section{METHODS}

Every baby was bled on seven occasions: at birth (after hepatitis B immunoglobulin injection) and at $1,2,3,6,12$, and 14 months of age. The mother's blood was drawn soon after delivery. Sera obtained were stored at $-20^{\circ} \mathrm{C}$ until tested. The collection of case information was detailed before. ${ }^{6}$

\section{CONTROLS}

A total of 100 children of 1 year old, who were randomly selected from our well baby clinic, were bled once after informed consent given by their parents or guardians. Their sera were tested for antibodies against cytomegalovirus, EpsteinBarr virus, and HHV-6 to serve as controls.

\section{ANTIBODY DETERMINATIONS}

IgG and IgM antibodies against cytomegalovirus (anticytomegalovirus) were tested by enzyme linked immunosorbent assay (ELISA). IgG anticytomegalovirus was tested with a kit from Behring, Holland. The results were expressed in anticytomegalovirus titres according to the manufacturer's instruction and titres lower than 100 were considered negative. $\operatorname{IgM}$ anticytomegalovirus was tested with a kit for Whittaker M A Bioproduct, Maryland, USA. The result was expressed as positive or negative.

IgG antibody against Epstein-Barr virus (antiEpstein-Barr virus) viral capsid antigen was tested by indirect immunofluorescence assay. P3HR-1 cells were induced by 5 '-iododeoxyuridine and then were fixed onto slides with cold acetone. The remaining procedures followed the standard immunofluorescence assay. IgG antibody against HHV-6 (anti-HHV-6) also was 
Table 1 Persistence time of maternally derived antibodies. Figures in parentheses show cumulative percentage. Some infants were infected by cytomegalovirus before complete disappearance of maternal derived cytomegalovirus antibodies. These infants were not included in the evaluation for cytomegalovirus in this table

\begin{tabular}{lcclllll}
\hline \multicolumn{8}{c}{ Persistence time (months) } \\
\cline { 2 - 8 } & $0-1$ & $1-2$ & $2-3$ & $3-6$ & $6-12$ & $12-14$ & $>14$ \\
\hline Epstein-Barr virus & $6(5)$ & $26(28)$ & $30(54)$ & $37(87)$ & $10(96)$ & $3(98)$ & $2(100)$ \\
Cytomegalovirus & $1(1)$ & $8(12)$ & $14(29)$ & $35(74)$ & $9(86)$ & $6(94)$ & $5(100)$ \\
HHV-6 & $28(32)$ & $28(64)$ & $16(83)$ & $15(100)$ & $0(100)$ & $0(100)$ & $0(100)$ \\
\hline
\end{tabular}

tested by indirect immunofluorescence assay and has been detailed before. ${ }^{8}$ The reciprocal of the highest serum dilution that gave positive fluorescence stain was taken as the titre of that serum. A titre lower than 10 was defined as seronegative.

RISK FACTORS

In the identification of risk factors, life table analysis was used for univariate analysis and Cox regression for multivariate analysis. The following factors were examined: (1) sex, (2) birth body weight, (3) Apgar scores, (4) ages of father and mother, (5) socioeconomic classes of parents, (6) breast feeding, (7) maternal serological status for HHV-6, Epstein-Barr virus, and cytomegalovirus, (8) the caregiver - that is, who the baby was taken care of by mainly - mother, grandparents, or babysitter, (9) administration of hepatitis B immunoglobulin, (10) number of exposed children including those in the home and of the babysitter, (11) household density (space of home divided by the number of people living there), (12) use of air conditioner, (13) behaviour facilitating the exchange of saliva as estimated by the frequency the baby put its fingers into another person's oral cavity, and (14) number of needle injections.

\section{Results}

MOTHERS' AND MATERNALLY DERIVED ANTIBODIES Almost all the mothers were seropositive for cytomegalovirus $(117 / 121 ; 96 \cdot 7 \%)$ and Epstein-

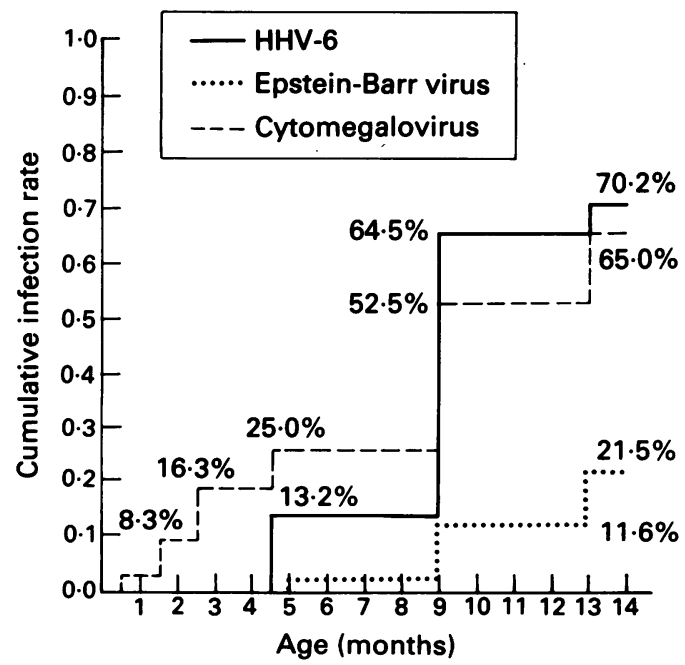

Figure 1 Cumulative rates of cytomegalovirus, Epstein$B$ arr virus, and $H H V-6$ infections.
Barr virus $(115 / 121 ; 95 \%)$ while $80 \%(97 / 121)$ of mothers were seropositive for HHV-6. About half of babies were born with antibody titres against these three viruses that were equal to maternal titres. Of the remaining half, roughly one quarter of babies had higher and one quarter had lower antibody titres compared with their mothers.

Maternally derived HHV-6 antibody disappeared at the fastest rate (table 1); by the age of 6 months, all babies lost their passive IgG antiHHV-6. Maternally derived antibodies against Epstein-Barr virus and cytomegalovirus decayed at a slower rate; the median durations for maternally derived antibodies against EpsteinBarr virus and cytomegalovirus to persist were both between three and six months.

TIME OF PRIMARY INFECTION

The time of primary infections is shown in fig 1 . All cases of primary HHV-6 and Epstein-Barr virus infections were diagnosed by seroconversion, that is, from seronegative to seropositive. Seventy nine children were infected with cytomegalovirus by the age of 14 months; 39 seroconverted against cytomegalovirus and 40 developed rising anticytomegalovirus titres in consecutive serum samples. In the 40 cases diagnosed by rising anticytomegalovirus titres, 23 of them had a positive IgM anticytomegalovirus. A twofold rise in cytomegalovirus titres was considered significant. Five cases had a titre rising between 1.3 to twofold and also without positive $\operatorname{IgM}$ antibody. The sera from these five cases were tested two to three times to make sure of the antibody rising. One possible reason for the antibody rising was because of cross reaction to other viruses such as Epstein-Barr virus or HHV-6. But no Epstein-Barr virus or HHV-6 infection was noted in that specific time interval, thus making cross reaction less likely. They were all seropositive against cytomegalovirus up to 14 months of age, that was also less likely from their titres immediately after birth. Considering all the evidence, we diagnosed these five cases as having cytomegalovirus infection.

No primary HHV-6 infection was noted before 2 months of age nor was there EpsteinBarr virus infection before 3 months of age. Primary cytomegalovirus infection occurred early, and by the age of 3 months $18.3 \%$ of infants had been infected and the proportion increased to $25 \%$ by 6 months of age. The monthly infection rates are shown in table 2 . The highest risk period for cytomegalovirus infection was between 1 and 3 months of age; that for HHV- 6 was between 6 and 12 months of age. The number of primary Epstein-Barr virus infections slowly increased from 3 months of age onward.

Table 2 Monthly infection rates of Epstein-Barr virus, cytomegalovirus, and HHV-6 (per cent)

\begin{tabular}{lllrlll}
\hline & \multicolumn{7}{l}{ Age interval (months) } \\
\cline { 2 - 7 } & $0-1$ & $1-2$ & $2-3$ & $3-6$ & $6-12$ & $12-14$ \\
\hline Epstein-Barr virus & 0 & 0 & 0 & $0 \cdot 6$ & $1 \cdot 7$ & $2 \cdot 5$ \\
Cytomegalovirus & $1 \cdot 7$ & $6 \cdot 6$ & 10 & $2 \cdot 2$ & $4 \cdot 6$ & $6 \cdot 3$ \\
HHV-6 & 0 & 0 & 1 & 4 & $8 \cdot 5$ & 3
\end{tabular}




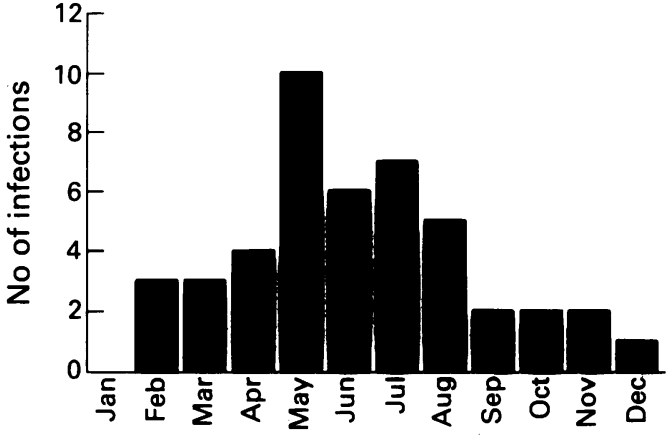

Figure 2 Monthly distribution of primary cytomegalovirus infections.

MONTHLY DISTRIBUTION OF CYTOMEGALOVIRUS INFECTION

Except for the infections occurring between 6 and 12 months of age, we could accurately estimate the time of primary infection. Therefore, it is possible to study the monthly distribution. As the number of cases of primary Epstein-Barr virus infection was small and most HHV-6 infections occurred between 6 and 12 months of age, only the monthly distribution of primary cytomegalovirus infections was calculated. This result is shown in fig 2 . We observed a clustering of primary cytomegalovirus infections from April to August.

PREVALENCE OF SEROPOSITIVITY IN THE CONTROI GROUP

A total of 100 children aged 1 year entered this study as a control group. The hepatitis B status of their mothers was unknown and they were chosen on a random base. The seropositive rates for Epstein-Barr virus and cytomegalovirus in these 100 children were $19 \%$ and $56 \%$ respectively. These figures were close to the seropositive rates in study infants at 1 year of age, $15 \cdot 7 \%$ and $64 \cdot 2 \%$ for Epstein-Barr virus and cytomegalovirus respectively. The differences of seropositive rates between study cases and controls were not statistically significant $(p=0.64$ for Epstein-Barr virus and $\mathbf{0 . 2 7}$ for cytomegalovirus by $\chi^{2}$ test with Yates's correction). The differences of the antibody titres were not significant either for cytomegalovirus ( $\mathrm{p}=0.12$ by Student's $t$ test after logarithmic transformation and $\mathrm{p}=$ 0.62 by Wilcoxon rank sum test) or Epstein-Barr virus ( $\mathrm{p}=0.54$ by Student's $t$ test after logarithmic transformation and $\mathrm{p}=\mathbf{0 . 8 6}$ by Wilcoxon rank rum test). The two groups were also comparable with regards to the status of $\mathrm{HHV}-6$ antibody. ${ }^{6}$

RISK FACTORS OF PRIMARY CYTOMEGALOVIRUS, EPSTEIN-BARR VIRUS, AND HHV-6 INFECTION

We did not find any risk factor associated with either primary $\mathrm{HHV}-6^{6}$ or primary Epstein-Barr virus infection. Life table analysis using the generalised Wilcoxon test identified the following factors, which were associated with the primary cytomegalovirus infection: (1) breast feeding ( $p=0.0006),(2)$ carer (highest risk for those cared for by a babysitter and lowest risk by mother, $\mathrm{p}=0.017$ ), (3) number of children in household (fewer children associated with higher risk, $p=0.03$ ), and (4) household density (high density having higher risk, $\mathrm{p}=0.03$ ).

Cox regression was used for multivariate analysis and significant factors entered into the model were breast feeding (odds ratio $2 \cdot 18,95 \%$ confidence interval (CI) $1 \cdot 3$ to $3 \cdot 66$ ), number of children in household (odds ratio 0.75 for per extra one child, $95 \%$ CI 0.58 to 0.96 ), and a dummy variable of carer as grandparents against babysitter (risk higher for caretaker being babysitter than being grandparents; odds ratio $2 \cdot 43$, $95 \%$ CI $1 \cdot 05$ to $5 \cdot 64$ ).

\section{Discussion}

In this study three distinct patterns of primary herpesvirus infection were observed. A substantial proportion $(18 \cdot 3 \%)$ of primary cytomegalovirus infections occurred in the first three months of life, then the risk of cytomegalovirus infection levelled off by the age of 14 months. Primary Epstein-Barr virus infections occurred much later than that of cytomegalovirus. During the first three months of life no Epstein-Barr virus infection was noted; after that, the risk of Epstein-Barr virus infection rose slowly and was maintained at a low level at 14 months of age. The pattern of primary HHV-6 infection differed from that of Epstein-Barr virus or cytomegalovirus infections. The infection of HHV-6 occurred late, similar to Epstein-Barr virus, but surged between 6 and 12 months of age (8.5\% of infants infected each month). Two thirds of the infants had been infected by the age of 1 year and the risk of HHV- 6 infection dropped to $3 \%$ between 12 and 14 months of age. As the host factors were the same, extrinsic factors were responsible for the three different patterns.

We suggest that the passive antibody the infant receives from its mother, the time for the infant to encounter the virus, and the amount of virus the infant is exposed to, all determine the infection patterns. As human herpesviruses cannot survive long in the environment or on a fomite, direct contact with human excretion is necessary for virus spread. ${ }^{1}$ The first possible contact happens when the baby passes through the birth canal and the second major one is ingestion of breast milk. A virus present in the birth canal and human breast milk would be an important agent of congenital and perinatal infections. Cytomegalovirus has been shown to replicate well in the birth canal during the third trimester of pregnancy ${ }^{9}$ and exist in human breast milk.10 I1 The situations for Epstein-Barr virus and HHV-6 are different; excretion of Epstein-Barr virus in the birth canal and breast milk is minimal or nil. ${ }^{12}{ }^{13}$ Although information about HHV-6 is limited, it has been shown from serology that there is no reactivation of HHV-6 in late pregnancy. ${ }^{14}$ These facts might explain the few infections of Epstein-Barr virus and HHV-6 in the first three months of life. After that time, the level of maternally derived antibody and the amount of virus the baby encountered determined the infection rate. In this study all maternally derived HHV-6 antibodies disappeared within six months but maternally 
derived Epstein-Barr virus antibody persisted much longer as shown in table 1 . Normal adults usually excrete large amounts of HHV $-6 . .^{15}$ In one study, by using the polymerase chain reaction, it was shown that the excretion of HHV-6 in the oropharynx was richer than that of Epstein-Barr virus. ${ }^{17}$ Early loss of passive antibody and high dose of virus in the environment could explain why such a large proportion of infants $(50 \%)$ became infected with HHV-6 between 6 and 12 months, while persistent passive antibody and relatively low amount of virus make the primary Epstein-Barr virus infection lag behind.

Although most babies in this study were born to $\mathrm{HBeAg}$ positive $\mathrm{HBsAg}$ carrier mothers, we believed that they were similar to other children in respect to primary Epstein-Barr virus, cytomegalovirus, and HHV-6 infections. A group of randomly selected infants were shown to be similar to the study cases both in seropositive rates and antibody titres. Besides, the fact that hepatitis B immunoglobulin injection was not a significant factor from either univariate or multivariate analysis also suggests that the status of maternal hepatitis B infection and immunoglobulin injection did not have a major influence.

The three factors significantly associated with primary cytomegalovirus infection in the Cox model were breast feeding, number of children in the household, and carer. Breast feeding increased the risk of cytomegalovirus infection, a fact that has been reported before and may be due to the presence of cytomegalovirus in breast milk and more intimate relationship between baby and its mother. ${ }^{11}$ ' One of the reasons why large number of children in the household and having a grandparent as carer were associated with a lesser risk of cytomegalovirus infection might be the age of carer. The excretion of cytomegalovirus in women is inversely related to age after puberty. ${ }^{18}$ The genital excretion of cytomegalovirus drops from $15 \%$ in teenage girls to an undetectable level in women older than 31 years. Urinary excretion of cytomegalovirus drops from $8 \%$ in young girls to nil in women older than 26 years. No excretion of cytomegalovirus in postmenopausal women is detected. Usually grandparents are older than babysitters and women with more children in the household are older than those with fewer. Therefore, it is possible that these two risk factors in the Cox model project the effect of age of the person directly taking care of the baby.

No risk factor was identified for primary Epstein-Barr virus infection in this study. We followed up this group of children to 14 months of age and only $21.5 \%$ of them were infected with Epstein-Barr virus. A study of older children is likely to be more appropriate in identifying risk factors associated with Epstein-Barr virus infection.

We observed clustering of primary cytomegalovirus infections from April through August. The connection of season and primary cytomegalovirus infection has not been reported before. This prospective study design facilitated the identification of the exact onset of infection. Previous studies usually relied on the reporting of cases. The reason for this seasonal variation is not clear. Whether a warm temperature activates the latent cytomegalovirus in seropositive carriers or facilitates spread is unknown but is worthy of further study.

In summary, the three human herpesvirus studied, Epstein-Barr virus, cytomegalovirus, and HHV-6 all behaved differently in causing primary infection. Cytomegalovirus caused infection soon after birth and the risk remained stable until the age of 14 months. HHV-6 was most prevalent when the baby was between 6 and 12 months of age. Epstein-Barr virus was not a common pathogen before 14 months of age compared with cytomegalovirus and HHV-6. Possible decisive factors might be reactivation in late pregnancy, level and duration of maternal antibody, and the presence of virus in saliva and breast milk.

I Straus SE. Introduction to herpesviridae. In: Mandell GL Douglas RG, Bennett JE, eds. Principles and practice of infectious diseases. 3rd Ed. New York: Churchill Livingstone, 1990: 1139-44.

2 Griffith PD, Baboonian C. A prospective study of primary cytomegalovirus infection during pregnancy: final report. BrF Obstet Gynaecol 1984; 91: 307-15.

3 Chandler SH, Alexander ER, Holms KK. Epidemiology of cytomegalovirus infection in a heterogeneous population of pregnant women. F Infect Dis 1985; 152: 249-95.

4 Arvin AM, Yeager AS. Other viral infections of the fetus and newborn. In: Remington JS, Klein JO, eds. Infectious diseases of the fetus and newborn infant. 3rd Ed. Philadelphia : Wiseases of the fetus and newborn

5 Salahuddin SZ, Ablashi DV, Markham PD, et al. Isolation of new virus, HBLV, in patients with lymphoproliferative disorders. Science 1986; 234: 596-601.

6 Huang LM, Lee CY, Chen JY, et al. Primary human herpesvirus-6 infections in children: a prospective study. Infect Dis 1992; 165: 1163-4.

7 Hinuma Y, Konn M, Yamaguchi K, Wudarski DJ, Blakeslee JR Jr, Grace JT Jr. Immunoflurescence and herpes-type particle in the P3HR-1 Burkitt lymphoma cell line. $\mathcal{F}$ Iiro 1967; 1: 1045-51.

8 Huang LM, Lee CY, Lin KS, et al. Human herpesvirus-6 associated with fatal hemophagocytic syndrome. Lancet 1990; 336: 60-1.

9 Stagno S, Reynolds DW, Tsiantos A, et al. Cervical crtomegalovirus excretion in pregnant and nonpregnant women: megalovirus excretion in pregnant and nonpregnant women:

10 Leinikki $\mathrm{R}$, Heinonen $\mathrm{K}$, Pettay $\mathrm{O}$. Incidence of cytomegalo virus infection in early childhood. Scand F Infect Dis 1972:4: virus

11 Stagno S, Reynolds DW, Pass RF, Alford CA. Breast milk and the risk of cytomegalovirus infection. $N$ Engl $\mathcal{F}$ Med 1980 302: 1073-6.

12 Visintine AJ, Gerber P, Nahmias AJ. Leukocyte transforming agent (Epstein-Barr virus) in newborn infants and older individuals. $\mathcal{F}$ Pediatr 1976; 89: 571-5.

13 Chang RS, Seto DY. Perinatal transmission by Epstein-Bar virus. Lancet 1979; ii: 201

14 Balachandra K, Ayuthaya PIN, Auwanit W, et al. Prevalence of antibody to human herpesvirus 6 in women and children. Microbiol Immunol 1989; 33: 515-8.

15 Pietroboni GR, Harnett GB, Bucens MR, Honess RW. Antibody to human herpesvirus 6 in saliva. Lancet 1988; i: 1059.

16 Levy JA, Ferro F, Greenspan D, Lennette ET. Frequent isolation of HHV -6 from saliva and high seroprevalence of the virus in the population. Lancet 1990; 335: 1047-50.

17 Gopal MR, Thomson BJ, Fox J, Tedder RS, Honess RW Detection by PCR of HHV-6 and EBV DNA in blood and otection by PCR of HHV -6 and EBV DNA in blood and oropharynx of healthy adults and HIV-seropositives. Lance

18 Knox GE, Pass RF, Reynolds DW, Stagno S, Alford CA Comparative prevalence of subclinical cytomegalovirus and herpes simplex virus infection in the genital and urinar tracts of low income, urban women. $\mathcal{F}$ Infect Dis 1979; 140 . 